\title{
A profile of coping skills in patients with polycystic ovarian syndrome
}

\author{
Aditi Prasad Chaudhari ${ }^{1}$, Kaustubh Mazumdar ${ }^{2}$, Pooja Deepak Mehta ${ }^{3}$ \\ ${ }^{1}$ Consultant Psychiatrist, \\ ${ }^{2}$ Consultant Psychiatrist and Medical Officer Incharge, Psychiatry Unit and Head - Medical Division, \\ ${ }^{3}$ Registrar, \\ Department of Psychiatry, Bhabha Atomic Research Centre Hospital, Anushaktinagar, Mumbai. \\ Corresponding author: Aditi Prasad Chaudhari \\ Email - aditidagaonkar@gmail.com
}

\begin{abstract}
Introduction: Coping skills adopted by patients suffering from chronic diseases such as Polycystic Ovarian Syndrome (PCOS) can impact the psychological well-being and outcome. This however has not been adequately studied in India. The aims of the study were to to study the type of coping skills used by the patients of PCOS, to evaluate any difference in coping skills between patients with and without psychiatric co-morbidity and to study any correlation between coping skills and quality of life and body-mass index.

Materials and Methods: 70 females in the reproductive age group (18-45 years) diagnosed with PCOS as per Rotterdam's Criteria without any pre-existing psychiatric illness were clinically interviewed for presence of anxiety and depression. Their coping skills were assessed using Brief Cope Scale. Their quality of life was evaluated using World Health Organization Quality Of Life -BREF Scale. The scores were compared using paired and unpaired t test and ANOVA.

Results: Patients used both adaptive and maladaptive coping skills but scores on adaptive coping skills were higher than those on maladaptive coping. Problem focused coping was significantly higher than both emotional coping and dysfunctional coping. There was no significant difference in the coping skills in patients with and without psychiatric morbidity. There was no significant correlation between coping and quality of life and body-mass index.

Conclusion: Coping skills did not have a significant impact on the psychiatric morbidity or quality of life or body-mass index among patient with PCOS.
\end{abstract}

Key words: PCOS, Coping skills, psychiatric morbidity, body-mass index.

(Paper received $-9^{\text {th }}$ March 2018, Peer review completed $-28^{\text {th }}$ March 2018)

(Accepted - 30 $0^{\text {th }}$ March 2018)

\section{INTRODUCTION}

Polycystic ovarian syndrome (PCOS) is the most common endocrine disorder among women of reproductive age [1]. The Indian Fertility Society has reported a prevalence of $3.7 \%$ to $22.5 \%$ in India [2]. PCOS presents with varying symptoms like menstrual abnormalities, hirsutism, fertility problems, weight gain or obesity, acne vulgaris and androgenic alopecia [1]. It can be regarded as a chronic illness because it is characterized by a prolonged course, lesser possibility of a complete cure and it requires an on-going adjustment to all aspects of daily life [3] e.g. management of physical symptoms, appearance, weight, diet, exercise and worry about future complications. Therefore, like in all such conditions, long term adaptation and a successful outcome could be shaped by the manner in which the person copes with these experiences [3]. Coping has been defined as "an individual's efforts to master demands (conditions of harm, threat, or 
challenge) that are appraised (or perceived) as exceeding or taxing his or her resources [4]." The experience of stress is thus a product of both the person and the situation. ${ }^{[5]}$ Coping describes the cognitions and behaviors used to manage the demands of stressful situations and it is a dynamic process that may present in different forms and serve different functions. Problem-focused coping describes direct efforts to solve the problem, including attempts to change the situation [5]. Emotion focused coping on the other hand aims to manage the emotions associated with a stressor so as to lessen emotional distress [5]. Maladaptive coping constitutes techniques that may reduce symptoms while maintaining and strengthening the disorder [6]. While the role of coping skills in many chronic ailments has been explored $[3,6]$, the literature on their role in PCOS is sparse [7-10]. The existing studies differ vastly in their methodology making it difficult to make any definite conclusions. However, they do suggest that maladaptive coping skills appear to worsen the emotional health [7] and quality of life [9] in these patients. More importantly, all of them have been reported from the western world and there is not a single published Indian study on this topic. This gap in knowledge is of concern. Coping is significant not just as a theoretical construct that impacts a person vulnerability to stress but also as a portal for therapeutic interventions [11]. To the best of our knowledge, this is the first comprehensive Indian study on coping skills in patients with PCOS.

\section{Aims and Objectives}

1. To study the type of coping skills used by the patients of PCOS.

2. To evaluate any difference in coping skills between patients with and without psychiatric co-morbidity.

3. To study any correlation between coping skills and Quality of life as well as Body-mass index.

\section{METHODOLOGY}

\section{Sample Selection}

This study was carried out at Department of Psychiatry in coordination with Department of Obstetrics and Gynaecology at BARC Hospital which is a Government Hospital in Mumbai, which exclusively catered to government employees or their family members who are covered under a contributory health scheme. It was a cross-sectional study conducted over a period of one year. As per the Indian Fertility Society, the prevalence of PCOS in India ranges from $3.7 \%$ to $22.5 \%$. So, for the purpose of the study, the prevalence was considered at $23 \%$, the confidence level at $95 \%$ and a margin of error at $10 \%$. The sample size was calculated using the formula, $\mathrm{n}=\mathrm{z}^{2} \times \mathrm{p}(1-\mathrm{p}) / \varepsilon^{2}$, wherein, $\mathrm{z}$ score for confidence level of $95 \%$ is 1.96 . The desired sample size was 68 which was rounded up to 70.After approval from the Ethics Committee of the Hospital, 70 consecutive patients who were diagnosed with PCOS as per Rotterdam's Criteria [12] at the Department of Gynaecology, were then referred to the Psychiatry out-patient department where they screened for any exclusion criteria. Finally, 70 consecutive patients aged between 18 to 45 years were enrolled after due informed consent. Convenience sampling was used.

\section{Inclusion criteria}

1. Patients diagnosed with PCOS as per Rotterdam's Criteria [12]

- Oligo-ovulation and/or anovulation

- Hyperandrogenism

- Polycystic ovaries

2. Adult female patients in the reproductive age group (18-45 years)

3. Patients willing to give informed consent.

\section{Exclusion criteria}

1. Patients who have consulted a psychiatrist or already diagnosed as having mental illness by selfreport on history and on perusal of past medical records.

2. Patients having concurrent significant medical illness. 


\section{Instruments}

1. A semi-structured proforma was designed to collect the demographic data of the respondents. The current mental health of the patient was assessed with history and mental status examination. The presence of anxiety and depressive disorders was established using ICD-10.

2. The Brief COPE Scale [13]: This scale was used to assess coping skills. It is a self-report questionnaire used to assess a number of different coping behaviors and thoughts, a person may have in response to a specific situation. It is the abridged version of the original COPE Inventory and assesses 14 coping types with 28 questions ( 2 questions per type). The responses to these questions are measured on a 4-point Likert-type scale with responses ranging from 1 ("I've not done this at all") to 4 ("I've been doing this a lot"). The scores (ranging from 2 to 8 ) and the means for each coping method are then calculated. A three category model of the Brief COPE was developed by Cooper and others [14] which divides the subscales into three categories viz. problem focused (active coping, planning, use of instrumental support); emotion focused (use of emotional support, positive reframing, acceptance, religion and humor) and dysfunctional coping strategies (venting, denial, substance use, behavioral disengagement, self-distraction and selfblame). The second model developed by Meyer [15] has divided the subscales under Adaptive Coping (all subscales on problem focused and emotion focused coping strategies) and Maladaptive Coping (dysfunctional coping strategies). Previous studies using this scale have used either of the two models. For the purpose of the present study, we have divided the coping skills into adaptive and maladaptive coping skills.

3. World Health Organization Quality Of Life -BREF (WHOQOL-BREF) Scale [16]: Quality of life is defined as individuals' perceptions of their position in life in the context of the culture and value systems in which they live and in relation to their goals, expectations, standards and concerns. The WHOQOL-BREF contains a total of 26 questions which are divided into 4 domains of physical health, psychological health, social and personal relationships and environmental and financial resources. The four domain scores denote an individual's perception of quality of life in each particular domain. Psychometric properties: The WHOQOL BREF scale has been shown to display good discriminant validity, content validity and test-rested reliability.

4. The Body Mass Index (BMI) [8] was calculated using the formula body weight in $\mathrm{kg}$ / (height in meters) $)^{2}$

\section{STATISTICAL ANALYSIS}

The data was pooled and statistically analysed using IBM SPSS 20 Software. The scores on the subscales of the Brief COPE scale have been expressed as mean scores with standard deviations. The scores on the different types of coping skills were compared using the paired t-test. The scores on the coping skills were compared between patients with and without psychiatric morbidity using the independent $t$ test and compared between normal weighted, over weight and obese females using the ANOVA. Scores on maladaptive coping were correlated with scores on the Quality of life while controlling for scores on the adaptive coping skills using partial correlations. A p value of less than 0.05 was regarded to be statistically significant.

\section{RESULTS}

A total of 70 females in the age group of 18 to 45 years were studied. The mean age of the sample was $27.65 \pm 7.60$ years. The socio-demographic profile of the study sample was as shown in Table 1 .

Type of coping skills used: 38 patients i.e. $54.28 \%$ patients used a combination of both adaptive and maladaptive coping styles. 32 i.e. $45.72 \%$ patients used only adaptive coping styles and none of the patients used only maladaptive coping styles. The type of coping skills used has been shown in Table 2. The mean scores on the adaptive coping skills were significantly higher than the scores on the maladaptive coping skills. $(\mathrm{t}=16.73$; $\mathrm{df}=69$; Sig. $=0.00 ; 95 \%$ Confidence Interval of the Difference - Lower $=0.924$ and Upper 1.175). Among the adaptive coping skills, the scores on the problem focused coping skills were 
significantly higher than those on emotion focused coping skills. $(t=4.40 ; \mathrm{df}=69 ;$ Sig. $0.00 ; 95 \%$ Confidence Interval of the Difference - Lower $=0.234$ and Upper 0.622).

Table 1: Socio-demographic profile of the study sample

\begin{tabular}{|c|c|c|c|}
\hline No & Domain & Frequency (n) & Percentage \\
\hline 1. & $\begin{array}{c}\text { Age Group: (in years) } \\
<25 \\
26-35 \\
>35 \text { years }\end{array}$ & $\begin{array}{l}31 \\
26 \\
13\end{array}$ & $\begin{array}{l}44.3 \\
37.1 \\
18.6\end{array}$ \\
\hline 2. & $\begin{array}{c}\text { Education: } \\
\text { Illiterate } \\
\text { Upto Class } 10 \\
\text { Upto Class } 12 \\
\text { Graduate } \\
\text { Post Graduate }\end{array}$ & $\begin{array}{c}0 \\
5 \\
24 \\
35 \\
6\end{array}$ & $\begin{array}{c}0 \\
7.1 \\
34.3 \\
50 \\
8.6\end{array}$ \\
\hline 3. & $\begin{array}{l}\text { Occupation: } \\
\text { Unemployed } \\
\text { Homemakers } \\
\text { Semi-skilled } \\
\text { Skilled } \\
\text { Professional } \\
\text { Student } \\
\end{array}$ & $\begin{array}{c}13 \\
15 \\
4 \\
9 \\
19 \\
10\end{array}$ & $\begin{array}{c}18.6 \\
21.4 \\
5.7 \\
12.9 \\
27.1 \\
14.3 \\
\end{array}$ \\
\hline 4. & $\begin{array}{l}\text { Marital Status: } \\
\text { Married } \\
\text { Unmarried }\end{array}$ & $\begin{array}{l}35 \\
35\end{array}$ & $\begin{array}{l}50 \\
50\end{array}$ \\
\hline & \multicolumn{3}{|c|}{ For Married Women $(\mathrm{n}=35)$} \\
\hline 5. & $\begin{array}{c}\text { Duration of marriage: } \\
<1 \text { year } \\
2-5 \text { years } \\
>5 \text { years } \\
\end{array}$ & $\begin{array}{c}1 \\
7 \\
27\end{array}$ & $\begin{array}{c}2.8 \\
20 \\
77.14\end{array}$ \\
\hline 6. & $\begin{array}{c}\text { Children: } \\
\text { Having children } \\
\text { Not having any children }\end{array}$ & $\begin{array}{l}17 \\
18\end{array}$ & $\begin{array}{l}48.57 \\
51.42\end{array}$ \\
\hline
\end{tabular}

Table 2: Type of coping skills used

\begin{tabular}{|c|c|}
\hline Coping skill & Mean scores with Standard Deviation \\
\hline Adaptive Coping Skills & $3.35 \pm 0.39$ \\
Problem Focused & $3.64 \pm 0.65$ \\
1. Use of instrumental support & $4.18 \pm 1.06$ \\
2. Active coping & $3.51 \pm 1.11$ \\
3. Planning & $3.32 \pm 1.00$ \\
Emotion Focused & $3.21 \pm 0.48$ \\
1. Use of emotional support & $3.58 \pm 1.08$ \\
2. Positive reframing & $3.50 \pm 1.35$ \\
3. Religion & $3.31 \pm 1.04$ \\
4. Acceptance & $3.07 \pm 0.99$ \\
5. Humour & $2.60 \pm 0.92$ \\
Maladaptive Coping Skills & $2.30 \pm 0.36$ \\
1. Self-blame & $2.11 \pm 0.43$ \\
2. Venting & $2.54 \pm 1.28$ \\
3. Behavioural Disengagement & $2.30 \pm 0.66$ \\
4. Denial & $2.28 \pm 0.70$ \\
5. Self-distraction & $2.65 \pm 1.04$ \\
6. Substance Use & $2.02 \pm 0.23$ \\
\hline
\end{tabular}


Table 3: Comparison of mean scores on coping skills between patients with and without psychiatric morbidity.

\begin{tabular}{|c|c|c|c|c|c|c|c|c|}
\hline Coping skill & $\begin{array}{c}\text { Psychiatric } \\
\text { morbidity }\end{array}$ & $\mathbf{N}$ & $\begin{array}{c}\text { Mean } \\
\text { Score }\end{array}$ & $\mathbf{F}$ & Sig. & $\mathbf{t}$ & df & $\begin{array}{c}\text { Sig. } \\
\text { 2-tailed }\end{array}$ \\
\hline Adaptive & $\begin{array}{c}\text { Anxiety } \\
\text { Present } \\
\text { Absent }\end{array}$ & 27 & 3.40 & 3.66 & 0.060 & 0.844 & 68 & 0.402 \\
\hline Maladaptive & $\begin{array}{c}\text { Anxiety } \\
\text { Present } \\
\text { Absent }\end{array}$ & 27 & 2.30 & 0.403 & 0.528 & 0.000 & 68 & 1.000 \\
\hline Adaptive & $\begin{array}{c}\text { Depression } \\
\text { Present } \\
\end{array}$ & 18 & 3.30 & & & & & \\
& Absent & 52 & 3.33 & 0.294 & 0.589 & 0.416 & 68 & 0.679 \\
\hline Maladaptive & $\begin{array}{c}\text { Depression } \\
\text { Present } \\
\text { Absent }\end{array}$ & 18 & 2.29 & 0.078 & 0.781 & -0.075 & 68 & 0.940 \\
& \multicolumn{2}{|c|}{52.30} & & & & & \\
\hline
\end{tabular}

Relationship between coping skills and psychiatric morbidity: A comparison of the mean scores on the different types of coping skills between patients with and without anxiety and depression was carried out using independent $t$ test but there was no significant difference between the two groups indicating that there was no association between psychiatric morbidity and coping skills for this study sample. This has been shown in Table 3.

Association between Coping Skills and Quality of Life (QOL): The scores on the four domains of the QOL were partially correlated with the scores on the maladaptive coping skills while controlling for the scores on adaptive coping skills.

Table 4: Correlation between scores on QOL with maladaptive coping skills while controlling for scores on adaptive coping skills

\begin{tabular}{|c|c|c|}
\hline Control variables & & Maladaptive Coping \\
\hline Adaptive coping & QOL I Physical Health & -0.075 \\
Correlation & 0.583 \\
& Significance $(2-$ tailed $)$ & 67 \\
df & \\
QOL II Psychological Health & 0.205 \\
Correlation & 0.091 \\
& Significance $(2-$ tailed $)$ & 67 \\
df & -0.037 \\
& CoL III Social and Personal Relationships & 0.764 \\
Correlation & 67 \\
& Significance $(2-$ tailed $)$ & 0.145 \\
df & 0.233 \\
& Correlation & 67 \\
\hline
\end{tabular}

Association between Coping Skills and Body Mass Index (BMI): There was no significant difference between women who were in the normal weight range, overweight and obese in their scores on coping skills (Table 5).

\section{DISCUSSION}

The purpose of the study was to describe the type of coping skills used by the women suffering from PCOS and examine their relationship with psychiatric morbidity, quality of life and BMI. Our findings suggest that these patients used both adaptive and maladaptive coping skills however the scores on adaptive skills were significantly higher than those on the maladaptive coping skills. Our findings are in contrast to a 
Table 5: Comparison of scores on coping skills between patients with normal weight, overweight and obesity

\begin{tabular}{|c|c|c|c|c|c|}
\hline BMI & $\begin{array}{c}\text { Normal Weight } \\
<25 \mathrm{~kg} / \mathrm{m}^{2}\end{array}$ & $\begin{array}{c}\text { Overweight } \\
25-30 \mathrm{~kg} / \mathrm{m}^{2}\end{array}$ & $\begin{array}{c}\text { Obese } \\
>30 \mathrm{~kg} / \mathrm{m}^{2}\end{array}$ & $\mathrm{~F}$ & Sig. \\
\hline $\mathrm{N}(\%)$ & $29(41.4 \%)$ & $23(32.8 \%)$ & $18(25.7 \%)$ & & \\
\hline Adaptive coping skills & 3.30 & 3.38 & 3.37 & 0.345 & 0.709 \\
\hline Maladaptive coping skills & 2.30 & 2.18 & 2.43 & 2.669 & 0.077 \\
\hline
\end{tabular}

German study [7] which reported that women with PCOS had higher scores on passive coping as compared to the general population and this was associated with anxiety, depression and a poorer quality of life. A study from Turkey [10] also reported that women with PCOS had a higher prevalence of dysfunctional coping styles as compared to controls. However a recent American study [8] has reported that women with PCOS use a combination of coping skills with adaptive coping skills being more frequently used, which is similar to our findings.

Traditionally, it has been reported that women tend to use more of emotion focused coping strategies [17]. This has not been reflected in our findings. Some of the factors that have been known to influence the use of problem focused coping strategies are the perception of threat and perception of change $[5,18]$. People are more likely to use these coping skills when they feel that the stressful situation is within their control and can be changed. Conversely, when they perceive a high level of threat, they may find it more difficult to use these methods for coping. PCOS does not usually present with any life-threatening complications and there are currently many therapeutic modalities available for the various symptoms it causes. The study population was being covered under a contributory health care scheme provided by the Government, making it easier for them to readily access good quality health care. This could be one of the reasons for our findings.

Our results also do not indicate any association between coping and psychiatric morbidity and quality of life. This again is in contrast to some of the earlier research which has shown maladaptive coping skills to be positively correlated with psychiatric morbidity [7-8] and inversely correlated with the quality of life $[7,9]$. There could be numerous reasons to account for the differences in findings. First and foremost, none of the patients in our study used only maladaptive coping and the scores on adaptive coping were significantly higher than the scores on maladaptive coping. Secondly, the other studies have made use of different psychometric instruments, thereby making it difficult to construct any comparisons. Thirdly, the socio-cultural differences in the population demographic may account for some of the variation. Last but not the least, however, the reasons can be explained by the understanding of the process of coping itself. In their comprehensive review on the subject, Folkman and others have emphasized on the fact that coping is not a stand-alone phenomenon [11]. It is embedded in a complex dynamic stress process that involves the person, the environment, and the relationship between them [11]. The manner in which, coping actually affects psychological, physiological, and behavioral outcomes both in the short- and the longer-term, does not lend itself to any simple explanations [11].

Most of the coping research states explicitly that coping processes themselves are not inherently good or bad $[11,18]$. Despite research efforts to identify the ideal coping response, there is no one strategy that is universally adaptive for all people across all situations [5]. A given coping process may be effective in one situation but not in another [11]. To determine whether or not a coping response was effective, we need to determine what constitutes successful coping. Therefore, as researchers, we fix outcome measures, which in the present study were psychiatric morbidity in terms of anxiety and depression, quality of life and BMI. However, the use of coping skills may be determined by goals of personal significance to the patient. Zeidner and Saklofske [19] named eight such goals: resolution of the conflict or stressful situation, reduction of physiological and biochemical reactions, reduction of psychological distress, normative social functioning; return to pre-stress activities, well-being of self and others affected by the situation, maintaining positive self-esteem, and perceived effectiveness. Thus, the role of coping skills cannot be altogether negated on account of their apparent lack of association with the chosen outcome variables as in the present study. There are studies which state that a broad repertoire of coping skills increases the 
possibility of a constructive response to a stressful medical condition [20]. Some authors recommend the expanding the patients' coping skills in a flexible manner to ensure the best outcome in the short and long term [21].

Obesity is frequently present in patients with PCOS and it plays an important role in the pathogenesis of the associated metabolic, endocrine and reproductive abnormalities [22]. Lifestyle changes, including diet, exercise, and behavioral modifications appear to improve these abnormalities and represent the first line of management for all overweight and obese patients with PCOS [22]. Some researchers postulate that specific skills, such as self-monitoring, countering negative thoughts, managing environmental cues and others, contribute to the success of lifestyle modification [23]. The authors felt that it was possible that coping skills could therefore impact the BMI. There was however, no association found between coping skills and BMI in our study. Similar results have been reported in a recent 2017 study [8]. On the other hand, a systematic review of psychological interventions for overweight and obesity suggests that behavioral and cognitive-behavioral strategies are effective weight-loss therapies, at least in the short-term [24]. The current scientific literature has mainly implicated insulin resistance in the etiopathogenesis of obesity in PCOS [23] but this was beyond the scope of the present study. More research would be needed to determine the interplay of organic and psychological factors in PCOS related obesity.

Limitations: This study has certain limitations as it is a cross-sectional study carried out on the employees of a central government health scheme and their family members, hence their characteristics may not be shared by the general population. There was no control group for comparison with the study population hence results had to be discussed with respect to the findings of previous studies. However, the authors believe that these limitations do not in any way undermine the significance of the study which is one of the first of its kind on coping in PCOS. Improvising on the findings of this research could go a long way in formulating the psychosocial interventions for this common endocrine disorder.

\section{CONCLUSIONS}

The patients with PCOS used either adaptive coping skills or a combination of adaptive and maladaptive skills. None of the patients used only maladaptive coping skills. Scores on adaptive coping were significantly higher than those on maladaptive coping. Coping did not show any significant association with psychiatric morbidity, quality of life or body mass index.

\section{REFERENCES}

1. Malik- Aslam A, Reaney MD, Speight J. The Suitability of Polycystic Ovary Syndrome-Specific Questionnaires for Measuring the Impact of PCOS on Quality of Life in Clinical Trials. International Society for Pharmacoeconomics and Outcomes Research (ISPOR) 2010;10;440-6.

2. Malik S, Jain K, Talwar P, Prasad S, Dhorepatil B. Management of Polycystic Ovary Syndrome in India. Fertil Sci Res 2014;1;23-43.

3. Kristofferzon ML, Lindqvist R, Nilsson A. Relationships between coping, coping resources and quality of life in patients with chronic illness: a pilot study. Scand J Caring Sci 2011;25;476-83.

4. Monat, A, Lazarus RS. Stress and Coping: An Anthology, 3rd edn., Columbia University Press, New York ; 1991.

5. Stephenson E, King DB, DeLongis A. Chapter 44: Coping Process. Stress: Concepts, Cognition, Emotion, and Behavior. 2016 Elsevier Inc.

6. Viganò C, Calzolari R, Marinaccio PM, Bezzio C, Furfaro , Gabriella BA, Maconi G. Unrevealed Depression Involves Dysfunctional Coping Strategies in Crohn's Disease Patients in Clinical Remission. Gastroenterol Res Pract 2016; e7803262.

7. Benson S, Hahn S, Tan S, Janssen OE, Schedlowski M, Elsenbruch S. Maladaptive Coping With Illness in Women With Polycystic Ovary Syndrome. JOGNN 2010;39;37-45.

8. Carron R, Kooienga S, Boyle DK, Alvero R. Coping in Women with Polycystic Ovary Syndrome: Implications for Practitioners. J Nurs Pract 2017;13(10):700-7.

9. Kolahi L, Asemi N, Mirzaei M, Adibi N, Beiraghdar M, Mehr AM.The relationship between quality of life and coping strategies in polycystic ovary syndrome patients. Adv Biomed Res 2015;4:168.

10. Ozenli Y, Hedardedeoglu B, Micozkadioglu I, Simsek E, Kilicdag EB, Bagis T. Anxiety, Depression and Ways of Coping Skills by Women with Polycystic Ovary Syndrome: A Controlled Study. J Turkish-German Gynecol Assoc 2008;9(4):190-4.

11. Folkman S and Moskowitz JT. Coping: Pitfalls and Promise. Ann Rev Psychol 2004;55:745-74. 
12. Rotterdam ESHRE/ASRM - Sponsored PCOS Consensus Workshop Group. Revised 2003 consensus on diagnostic criteria and long term health risks related to polycystic ovary syndrome. Fertil Steril 2004;81:1925 .

13. Carver CS. You want to measure coping but your protocol's too long: Consider the brief COPE. Int J Behav Med 1997;4(1);92-100.

14. Cooper C, Katona C, Orrell M, Livingston G. Coping strategies and anxiety in caregivers of people with Alzheimer's Disease: The LASER-AD study. J Affect Disord 2006;90(1):15-20.

15. Meyer B. Coping with severe mental illness: Relations of the brief COPE with symptoms, functioning and well being. J Psychopathol Behav Asses 2001;23(4):265-77.

16. WHO QOL Group. Development of the World Health Organization WHOQOL-BREF quality of life assessment. Psychol Med 1998;28(3):551-8.

17. Kelly MM, Tyrka AR, Price LH, Carpenter LL. Sex Differences in the use of coping strategies: Predictors of anxiety and depressive symptoms. Depress Anxiety 2008;25(10):839-46.

18. Lazarus RS, Folkman S. Stress, Appraisal, and Coping. New York, NY:Springer Publishing Company; 1984.

19. Zeidner M, Saklofske D. 1996. Adaptive and maladaptive coping. In Zeidner M, Endler NS (eds). Handbook of Coping. Pages 505 - 31. New York: Wiley ; 1996.

20. Taylor SE. Health Psychology, Boston. MA, McGraw-Hill, 1999.

21. Kaupp JW, Rapoprt-Hubschmann N, Spiegel D: Psychosocial Treatments in Textbook of Psychosomatic Medicine. Editor: Levenson JL. Pages 924 - 25. American Psychiatric Publishing. 2005.

22. D. Panidis, E. Papadakis, C. Vosnakis, P. Chatzis, I. Katsikis. Lifestyle intervention and anti-obesity therapies in the polycystic ovary syndrome: impact on metabolism and fertility. Endocrine. Springer; 2013.

23. Moran LJ, Lombard CB, Lim S, Noakes M, Teede HJ. Polycystic ovary syndrome and weight management. Women's Health 2010;6(2):271-83.

24. Shaw K, O'Rourke P, Del Mar C, Kenardy J: Psychological interventions for overweight or obesity. Cochrane Database Syst Rev 2005;2:CD003818.

$* * * * * * * * * * * * * * * * * * * * * * * * * * * * * * * * * * *$

Acknowledgements - The authors would like to thank Dr Amrita Misri - Head, Department of Obstetrics and Gynaecology for granting us permission to conduct the study on patients with PCOS presenting to the Department of Obstetrics and Gynaecology.

$$
\begin{gathered}
\text { Conflict of Interest - Nil; } \\
\text { Funding - Nil. }
\end{gathered}
$$

